\title{
Diagnosis of Invasive Cervical Resorption by Using Cone Beam Computed Tomography: Report of Two Cases
}

\author{
Karla de Faria VASCONCELOS \\ Yuri NEJAIM \\ Francisco HAITER NETO \\ Frab Norberto BÓSCOLO \\ Department of Oral Diagnosis, Division of Oral Radiology, Piracicaba Dental School, \\ UNICAMP - University of Campinas, Piracicaba, SP, Brazil
}

\begin{abstract}
A radiographic interpretation is essential to the diagnosis of invasive cervical resorption (ICR) and the difficulty in distinguishing this lesion from internal root resorption has been highlighted in the literature. This paper reports the use of cone beam computed tomography $(\mathrm{CBCT})$ in the diagnosis of ICR. The cases reports describe how CBCT can be used to make a differential diagnosis and also show that the use of this technology can provide relevant information on the location and nature of root resorption, which conventional radiographs cannot. As a result, the root canal treatment was not initially considered. The patients will be monitored and will undergo a scan after a short period of time to detect any small changes. It was observed that both cases benefited from CBCT in the diagnosis of ICR, because this imaging modality determined the real extent of resorption and possible points of communication with the periodontal space.
\end{abstract}

Key Words: cone beam computed tomography, diagnosis, root resorption.

\section{INTRODUCTION}

Invasive cervical resorption (ICR) is an uncommon type of external tooth resorption, which can affect any tooth in permanent dentition (1). When it occurs in the crown, it can be termed invasive coronal resorption, while in a more apical location it may be termed invasive radicular resorption. Its etiology is poorly understood, but trauma, orthodontics and periodontal treatment have been most frequently cited in the literature (2).

A radiographic interpretation is decisive for the diagnosis of invasive cervical resorption and the difficulty in distinguishing invasive cervical resorption from internal resorption has been reported $(2,3)$. An accurate diagnosis is essential for both tooth treatment and prognosis, while misdiagnosis can result in inappropriate treatment and tooth loss.

Both lesions may have a similar radiographic appearance. Internal root resorption (IRR) lesions are smooth and generally symmetrically distributed over the root with uniform density. As the lesion affects its course the pulp chamber or root canal outline cannot be followed through because the canal walls essentially balloon out (4).

The radiographic appearance of ICR depends on the severity of the lesion. Early lesions appear as diffuse radiolucencies in the cervical region of the tooth and the border of the defect is usually poorly defined. The root canal walls are visible and run vertically through the radiolucent defect, indicating that the lesion lies on the external surface of the root $(2,5)$. A positive response to vitality tests is usually observed.

However, intraoral radiographs do not indicate the true dimensions of such lesions (6). The resorption defect may spread within the root in all directions and this may not be reflected in the size or position of the radiolucency detected in the radiograph $(3,7)$. 
There is no doubt that recent improvements in digital imaging systems have brought numerous benefits to endodontic practice (8). The advent of threedimensional imaging has provided the endodontist with previously unavailable tools which facilitate interactive image manipulation and enhancement.

Cone beam computed tomography has enhanced radiographic diagnosis $(7,9)$. It provides greater threedimensional geometric accuracy than conventional radiography (10). Several case reports and case series have confirmed the benefits of CBCT in diagnosing and managing resorptive lesions $(11,12)$.

The two cases reported herein demonstrate how $\mathrm{CBCT}$ can be used to make a differential diagnosis between internal root resorption and invasive cervical resorption. The advantages and limitations of $\mathrm{CBCT}$ parameters are discussed and it is shown that $\mathrm{CBCT}$ can provide relevant information on the location and nature of root resorptive defects, which conventional radiographs fail to do (13).

\section{CASE REPORT}

\section{Case 1}

A 25-year-old Caucasian male patient attended the Oral Radiology Clinic at Piracicaba Dental School, UNICAMP, Brazil, for diagnostic purposes. There were no pain symptoms, discoloration of tooth crown or tooth mobility (Fig. 1A). On analyzing the panoramic radiograph, a change was seen in the root canal of the mandibular left canine. A periapical radiographic examination using a paralleling technique was proposed for further evaluation (Fig. 1B). In the periapical radiograph an enlargement of the root canal was seen in the cervical and medium thirds of the root, suggestive of internal or external cervical resorption. In order to evaluate the real extent and degree of impairment in
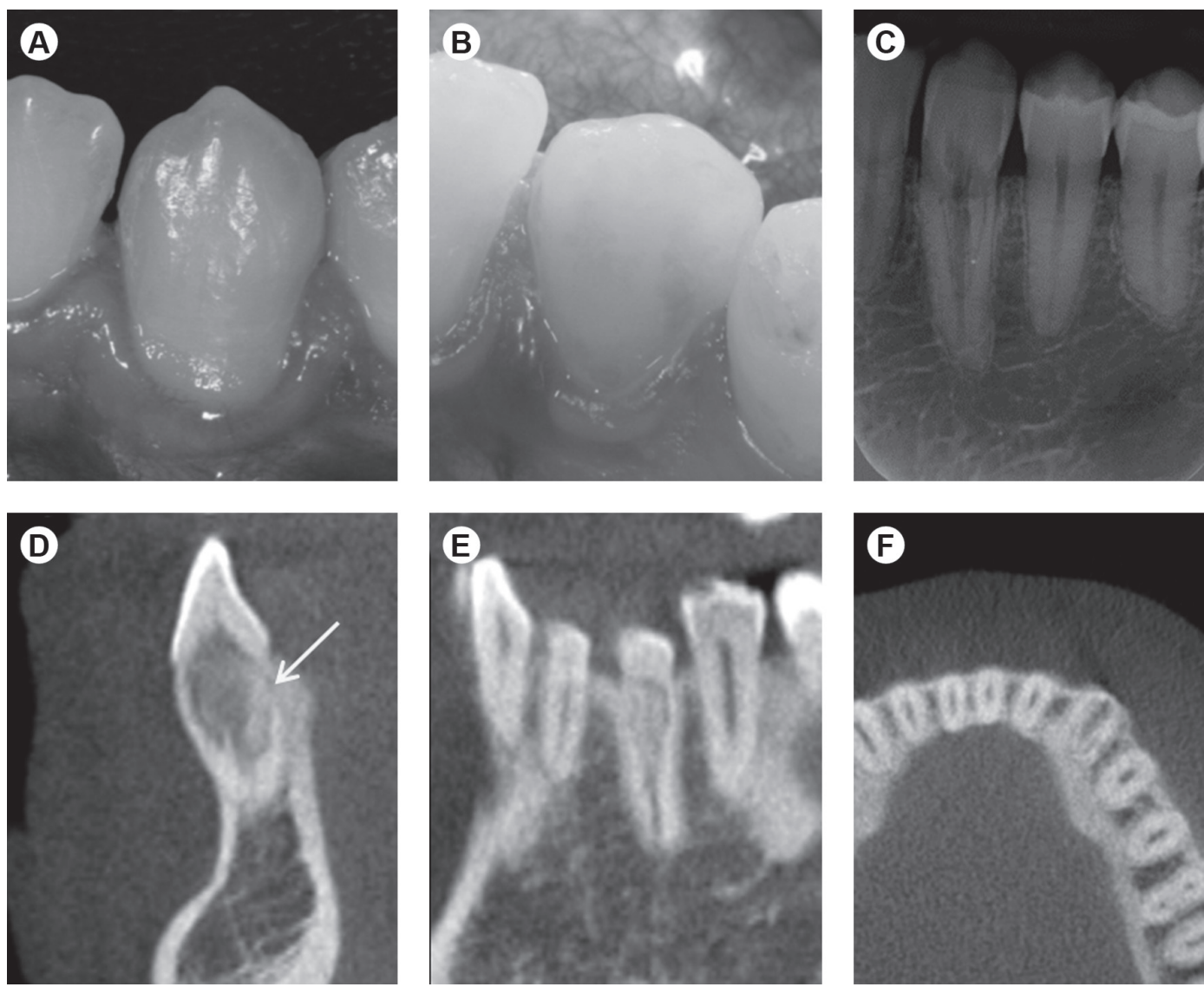

Figure 1. Case 1. A-B: Clinical views showing normal status of crowned tooth 33. C: Periapical radiograph showing an enlargement of the root canal in the coronal and middle thirds of the root. D: Cross-sectional CBCT slice revealing a lingual perforation (arrow). E: Coronal CBCT slice showing the diffuse radiolucencies in the root canal. F: Axial CBCT slice showing the cloudy radiolucency. 
the condition detected radiographically, a dynamic evaluation by CBCT was done, which showed a possible root canal communication with the outside by lingual perforation (Fig. 1D-F). Faced with this clinical finding, the patient was interviewed and reported the use of orthodontic appliance at two different times totaling a period of approximately 4 years. Relevant information to the case were the fact that serial grinding had been done on the distal surface of the mandibular left and right canines to create space in the dental arch and the positive response to pulp vitality cold test. The patient was called after 6 months and the same clinical conditions were observed. There were no pain symptoms, discoloration of the crown or tooth mobility and pulp vitality was preserved. Dynamic evaluation by CBCT was done and revealed the same condition, without evolution (Fig. 2). After verbal and written consent had been obtained, a limited CBCT scan of the region of interest was carried out using i-CAT (Imaging Sciences International, Hatfield, PA, USA) with exposure parameters of $120 \mathrm{kV}$, $37.07 \mathrm{mAs}, 26.9 \mathrm{~s}$, a voxel size of $0.25 \mathrm{~mm}, 6 \mathrm{~cm} \times 16$ $\mathrm{cm}$ of FOV, this which was followed up by a dynamic analysis of the axial, sagittal and coronal slices.

\section{Case 2}

A 22-year-old Caucasian female patient attended the Oral Radiology Clinic at the Piracicaba Dental School, UNICAMP, Brazil, for diagnostic purposes, presenting a similar change in the root canal of the mandibular left canine as the one described in Case 1. The same approach was adopted. CBCT was performed to retrieve any additional information and possible root canal communication with the external environment (Fig. 3). In the clinical interview, the patient reported having used an orthodontic appliance for 2 years and had completed the treatment 1 year before seeking our clinic. There were no pain symptoms; discoloration of the crown or tooth mobility and a positive response to cold was also observed.

\section{DISCUSSION}

Heithersay (5) wrote a series of classical articles in which the features, possible predisposing factors, clinical classification and treatment for ICR were described. According to Heithersay's classification, both cases reported herein would be in Class 4, with a large invasive resorptive process, which had extended beyond the coronal third of the root.

A proper diagnosis of root resorption lesions is essential for the choice of treatment and consequently better prognosis for the tooth. As the literature shows, great difficulty is experienced when making a differential diagnosis between IRR and ICR $(11,12,14)$. Each case requires its own specific treatment.

In both Cases 1 and 2, lesions were found in the left mandibular canine teeth during routine radiographic examinations (panoramic and periapical radiographs). These two-dimensional images revealed changes in the root canal but the actual extent and location of the lesions were not fully clear. Two diagnostic hypotheses were first established: internal root resorption or invasive cervical resorption.
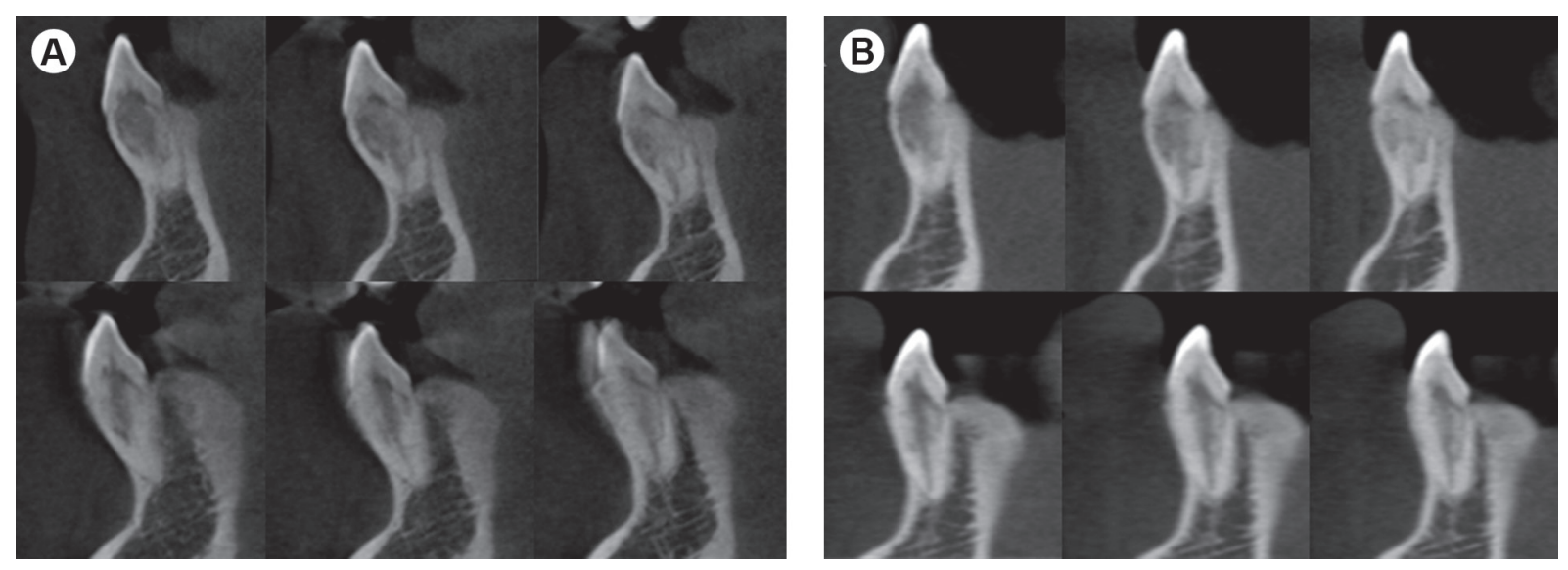

Figure 2. Case 1. Comparison by cone beam computed tomography (CBCT) showed the same condition over time, without evolution. Cross-sectional CBCT slices at the beginning of treatment (A) and after 6 months (B). 
Available research indicates that in twodimensional imaging modalities the location and nature of the root resorptive defect may not be clear. The parallax principle is a technique used in making a differential diagnosis between the internal root resorption and the invasive cervical resorption $(3,15)$. However, intraoral radiographs do not allow for assessment of the actual extent of such lesions $(4,16)$ because they can diffuse in all directions without changing the size of the root or the position of the radiolucencies detected on radiographs (3).

As the introduction of CBCT to dentistry and its availability in the dental office have opened up new possibilities in maxillofacial imaging, a CBCT image was prescribed to assess the nature, location and severity of the resorptive lesion. However, as the effective radiation dose to patients is higher than in conventional intraoral radiography, the decision to indicate $\mathrm{CBCT}$ in the management of endodontic problems must be made on a case-by-case basis and only when sufficient diagnostic information is not available from other diagnostic tests $(13,17)$.

$\mathrm{CBCT}$ voxels are isotropic, which ensures that the images produced are geometrically accurate and image measurements are free from distortion (18). The resolution parameters adopted in these two cases: FOV of $6 \mathrm{~cm} \times 16 \mathrm{~cm}$ and a voxel size of $0.25 \mathrm{~mm}$, corroborated with the diagnosis. In general, it could be stated that small FOV and high-resolution scans are optimal for detailed diagnosis, with potential uses of $\mathrm{CBCT}$ in the assessment and management of endodontic problems $(19,20)$.

A previous study (21) reported CBCT to be $100 \%$ accurate in the diagnosis of the presence and type of root resorption and that the overall sensitivity of intraoral radiographs was lower than $\mathrm{CBCT}$. A recent study (5) comparing $\mathrm{CBCT}$ and periapical radiography showed that $\mathrm{CBCT}$ was significantly superior in the detection of
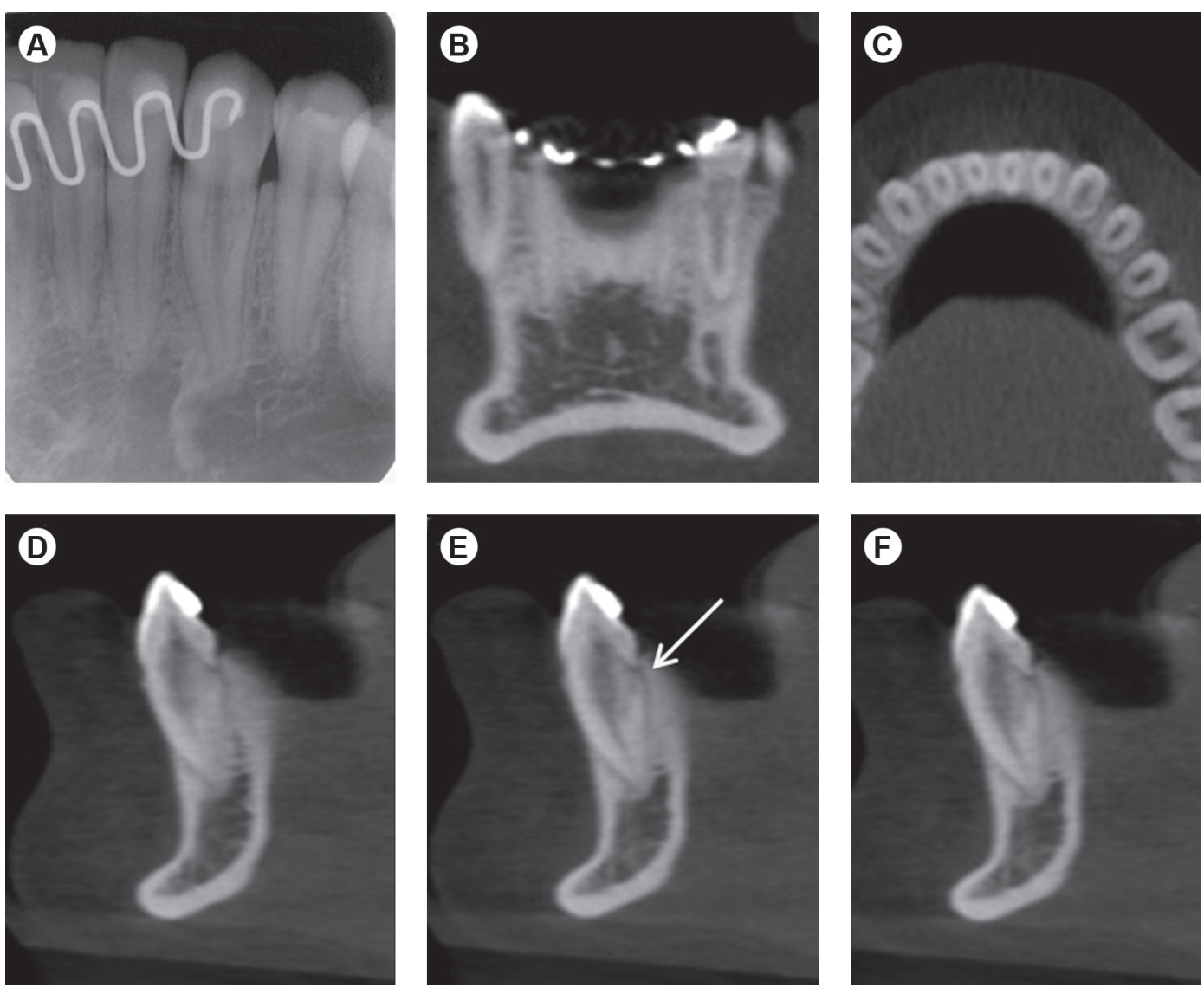

Figure 3. Case 2. A: Periapical radiograph demonstrating the cloudy radiolucency of the root canal in the coronal and middle thirds of the root. Coronal (B) and axial (C) CBCT slices showing the diffuse radiolucencies in the root canal, and cross-sectional CBCT slices (D-F) revealing a lingual perforation (arrow). 
external resorption $(\mathrm{p}<0.05)$. CBCT tended to be superior in the identification of perforations, but no significant difference was detected ( $p>0.05)$. As to the detection of fractured files, a slight superiority of radiography was apparent, but without statistical significance ( $\mathrm{p}>0.05$ ). For post-deviation identification purposes, CBCT was superior when compared with conventional radiography but there was no significant difference $(\mathrm{p}>0.05)$.

In another study (6), when the diagnostic accuracy of small volume CBCT and intraoral periapical radiography was compared for the detection of simulated external inflammatory root resorption, the examiners were significantly more accurate on identifying the exact location of the resorption lesions with CBCT than they were with radiographs $(p<0.001)$. In the two cases reported in this paper, a dynamic evaluation by CBCT made it possible to assess the real extent of the root defect, as it can reveal possible points of communication with the periodontal space (Fig. 1D and 3E). It also showed a diffuse pattern and irregular resorption, corroborating the diagnosis of invasive cervical resorption.

As both patients had completed orthodontic treatment and there were no clinical signs or symptoms, they were informed of the findings of the investigations and the possibility of monitoring, and a non-intervention was discussed. Because there were no clinical symptoms or signs of pulpal damage and, according to Heithersay (5), teeth with Class 4 lesions present unsatisfactory treatment and prognosis, and in his opinion one of the options could be non-intervention, root canal treatment was not initially considered.

The patients will be monitored and will undergo a scan after a short period of time to detect any small changes. In Case 1, there were no changes during subsequent follow up period of 6 moths. The threedimensional dental dataset not only contributes to the diagnostic field, but can also be applied to surgical and therapeutic planning (22). It is superior to other methods when used in situations in which a clinical follow-up is essential (23). These reasons justify the use of CBCT for follow-up in both cases.

In conclusion, the cases illustrate the advantages of CBCT in the diagnosis of cervical invasive resorption. This imaging modality determines the real extent and possible points of communication with the periodontal space. The combination with clinical information was essential for the differential diagnosis between internal root resorption and the invasive cervical resorption.

\section{RESUMO}

A interpretação radiográfica é essencial para o diagnóstico da reabsorção cervical invasiva (RCI) e a dificuldade em distingui-la da reabsorção radicular interna tem sido destacada na literatura. Este trabalho relata o uso da tomografia computadorizada de feixe cônico (TCFC) no diagnóstico da RCI. Os casos descrevem como a TCFC pode ser utilizada no diagnóstico diferencial e relatam também como esta tecnologia pode providenciar relevantes informações sobre a localização e natureza das reabsorções radiculares, limitadas pelas radiografias convencionais. Como resultado, o tratamento do canal radicular não foi inicialmente considerado. Os pacientes serão acompanhados e após curto período de tempo novos exames tomográficos serão realizados no intuito de detectar pequenas alterações. Observa-se que ambos os casos beneficiaram-se com o uso da TCFC no diagnóstico de RCI, pois esta modalidade de imagem determinou a real extensão da reabsorção e possíveis pontos de comunicação com o espaço periodontal.

\section{REFERENCES}

1. Heithersay GS. Clinical, radiologic, and histopathologic features of invasive cervical resorption. Quintessence Int 1999;30:27-37.

2. Tronstad L. Root resorption - etiology, terminology and clinical manifestations. Endod Dent Traumatol 1988;4:241-252.

3. Patel S, Dawood A, Whaites E, Pitt Ford T. The potential applications of cone beam computed tomography in the management of endodontic problems. Int Endod J 2007;40:818830 .

4. Gartner AH, Mark T, Somerlott RG, Walsh LC. Differential diagnosis of internal and external cervical resorption. J Endod 1976;2:329-334.

5. Heithersay GS. Invasive cervical resorption. Endod Topics 2004;7:73-92.

6. Kim E, Kim K-D, Roh B-D, Cho Y-S, Lee S-J. Computed tomography as a diagnostic aid for extracanal invasive resorption. J Endod 2003;29:463-465.

7. Dawood A, Patel S, Brown J. Cone beam CT in dental practice. $\mathrm{Br}$ Dent J 2009;207:23-28.

8. Nair MK, Nair UP. Digital and advanced imaging in Endodontics: A Review. Int J Endod 2007;33:1-6.

9. Tyndall DA, Rathore S. Cone-beam CT diagnostic applications: caries, periodontal bone assessment, and endodontic applications. Dent Clin North Am 2008;52:825-841.

10. Murmalla R, Wortche R, Muhling J, Hassfeld S. Geometric accuracy of the NewTom 9000 Cone Beam CT. Dentomaxillofac Radiol 2005;34:28-31.

11. Cohenca N, Simon JH, Marhtur A, Malfaz JM. Clinical indications for digital imaging in dento-alveolar trauma: part 2 - Root resorption. Dent Traumatol 2007;23:105-113.

12. Cotton TP, Geisler TM, Holden DT, Schwartz SA, Schindler WG. Endodontic applications of CBCT. J Endod 2007;9:1121-1132.

13. D‘Addazio PSS, Campos CN, Özcan M, Teixeira HGC, Passoni RM, Carvalho ACP. A comparative study between cone-beam computed tomography and periapical radiographs in the diagnosis of simulated endodontic complications. Int Endod J 2011;44:218224.

14. Schwartz RS, Robbins W, Rindler E. Management of invasive cervical resorption: observations from three private practices and a report of three cases. J Endod 2010;36:1721-1730.

15. Haapasalo M, Endal U. Internal inflammatory resorption: the 
unknown resorption of the tooth. Endod Topics 2006;14:60-79

16. Kamburoglu K, Barenboim SF, Aritürk T, Kaffe I. Quantitative measurements obtained by micro-computed tomography and confocal laser scanning microscopy. Dentomaxillofac Radiol 2008;37:385-391.

17. Durack C, Patel S, Davies J, Wilson R, Mannocci F. Diagnostic accuracy of small volume cone beam computed tomography and intraoral periapical radiography for the detection of simulated external inflammatory root resorption. Int Endod J 2011;44:136147.

18. Scarfe WC, Farman AG, Sukovic P. Clinical applications of conebeam computed tomography in dental practice. J Can Dent Assoc 2006; $72: 75-80$

19. Liang X, Jacobs R, Hassan B, Li L, Pauwels R, Corpas L, et al. A Comparative evaluation of cone beam computed tomography (CBCT) and multi-slice CT (MSCT) Part I. On subjective image quality. Eur J Radiol 2010;75:265-269.

20. Durack C, Patel S. Cone beam computed tomography in Endodontics. Braz Dent J 2012;23:179-191.

21. Patel S, Dawood A, Wilson R, Horner K, Mannocci F. The detection and management of root resorption lesions using intraoral radiography and cone beam computed tomography - an in vivo investigation. Int Endod J 2009;42:831-838.

22. Jacobs R. Dental cone beam CT and its justified use in oral health care. JBR-BTR 2011,94:254-265.

23. Estrela C, Bueno MR, Alencar AHG, Mattar R, Neto JV, Azevedo $\mathrm{BC}$, et al.. Method to evaluate inflammatory root resorption by using cone beam computed tomography. J Endod 2009;35:14911497.

Received May 22, 2012

Accepted October 31, 2012 